\title{
Limited Exposure to Ambient Ultraviolet Radiation and 25- Hydroxyvitamin D Levels: A Systematic Review
}

Running head: Limited UVR exposure and vitamin D levels

Word count: 3272

5 figures

S. A. Rice ${ }^{1}$, M. Carpenter ${ }^{1}$, A. Fityan ${ }^{2}$, L. M. Vearncombe ${ }^{2}$, M. ArdernJones $^{1,2}$, A. A. Jackson ${ }^{3}$, C. Cooper ${ }^{4,5}$, J. Baird ${ }^{4}$ and E. Healy ${ }^{1,2}$

${ }^{1}$ Dermatopharmacology, Sir Henry Wellcome Laboratories, Faculty of Medicine, University of Southampton, Southampton, Hampshire, UK

${ }^{2}$ Southampton Dermatology Centre, Royal South Hants Hospital, University Hospitals Southampton NHS Foundation Trust, Hampshire, UK

${ }^{3} \mathrm{NIHR}$ Biomedical Research Centre (Nutrition), University of Southampton, Southampton, Hampshire, UK

${ }^{4}$ MRC Lifecourse Epidemiology Unit, Faculty of Medicine, University of Southampton, Southampton, Hampshire, UK

${ }^{5} \mathrm{NIHR}$ Musculoskeletal BRU, University of Oxford, Oxford, Oxfordshire, UK

Correspondence: Eugene Healy, Dermatopharmacology, University of Southampton, Sir Henry Wellcome Laboratories, Southampton General Hospital, Southampton, Hampshire, SO16 6YD, UK. Tel: +44(0)2380795756; e-mail: ehealy@soton.ac.uk 
Funding: This study was supported by the National Institute for Health Research (NIHR) via a NIHR Academic Clinical Fellowship (SAR).

No conflicts of interest to declare.

List of abbreviations: 25OHD, 25-hydroxyvitamin D; UVR, ultraviolet radiation

\section{What's already known about this topic?}

- Hypovitaminosis D is common worldwide.

- Adequate vitamin D levels are associated with improved health outcomes.

- Vitamin D can be obtained from the diet, through oral supplementation or synthesised in human skin following exposure to ultraviolet radiation (UVR).

- Many authorities advocate that UVR exposure is essential for adequate vitamin D levels.

- UVR exposure can lead to skin cancer development, resulting in approximately 13 million skin cancers worldwide per annum.

\section{What does this study add?}

- This study demonstrates that many healthy adults in different population groups across the world can maintain adequate serum vitamin D levels despite negligible UVR exposure for several months of the year. 
- Public health campaigns promoting a high vitamin $\mathrm{D}$ diet or supplements to healthy adults could positively impact on the burden to the individual and the health service of inadequate vitamin $D$ levels and could avoid negative sequelae of UVR exposure. 


\section{Abstract}

Background: Vitamin D can be synthesised following exposure to ultraviolet radiation (UVR), ingested in the diet or provided through oral supplementation. The medical literature frequently states that humans obtain most of their vitamin D from sunshine and that UVR exposure is essential to maintain vitamin D levels. Objective: A systematic review was conducted to determine the requirement for UVR in maintaining adequate $(>50 \mathrm{nmol} / \mathrm{L})$ serum 25-hydroxyvitamin D (25OHD) levels. Method: Studies reporting serum 25OHD during situations of negligible UVR exposure were sought. 41 studies (from a search yielding 42,698 articles) totalling 4,211 healthy adults met the inclusion criteria, providing 56 datasets from different population groups. Results: Over $50 \%$ of subjects had $>50 \mathrm{nmol} / \mathrm{L} 25 \mathrm{OHD}$ in 10 of 19 datasets reporting winter levels in areas with limited UVR. In addition, $>50 \%$ of subjects had adequate $25 \mathrm{OHD}$ levels in 4 of 12 datasets from polar regions during periods of negligible UVR, 1 of 9 datasets documenting clothing-related minimal UVR and 2 of 8 datasets detailing employment-related minimal UVR. Conclusion: The data demonstrate that many adults maintain adequate serum vitamin D levels despite negligible UVR exposure for several months. However, we acknowledge that preceding UVR exposure leading to vitamin D storage and delayed release may account for this maintenance of adequate serum vitamin $\mathrm{D}$ levels. There remains a need for further research on whether UVR exposure is required for longer-term maintenance of adequate vitamin D levels. 


\section{Introduction}

A growing evidence base suggests that adequate levels of vitamin D are associated with superior health outcomes. These include improved bone ${ }^{1}$ and cardiovascular health ${ }^{2}$, lower incidence/activity of autoimmune disease ${ }^{3,4}$, reduced cancer incidence/mortality ${ }^{5}$ and reduced all-cause mortality ${ }^{6}$. Although vitamin D levels in humans can be increased by dietary intake, dietary supplementation and ultraviolet radiation (UVR) exposure ${ }^{7}$, hypovitaminosis $D$ remains prevalent worldwide ${ }^{8,9}$. The medical literature frequently states that humans obtain most of their vitamin D from sunshine and that UVR exposure is essential to maintain vitamin D levels ${ }^{10,11}$. Consequently, public health guidelines frequently encourage sun exposure for maintenance of adequate vitamin D levels ${ }^{12,13}$. However, UVR has detrimental effects on human health and the World Health Organisation estimates UVR exposure results in loss of 1.5 million disability-adjusted life years and 60,000 premature deaths worldwide annually, including 200,000 melanomas, 12.8 million non-melanoma skin cancers, and $30 \%$ of eight million cataracts ${ }^{14}$. Interventional studies demonstrate that UVR can increase vitamin D in humans, but extrapolating from them to suggest UVR is necessary for adequate vitamin $D$ levels may be erroneous. A recent modelling study reported that $10-20$ minutes of sun exposure (often advocated by public health statements) is inadequate to significantly boost serum vitamin $D$ levels and that sufficient sun exposure to achieve worthwhile benefit would compromise skin health ${ }^{15}$. However, a trial employing artificial UVR three times weekly for six weeks suggested one can achieve adequate serum $250 H D$ levels from this amount of midday sunshine once individuals (white 
Caucasians) expose $35 \%$ of their body surface area to sunshine incident vertically on exposed $\operatorname{skin}^{16}$. Limited data exist for weighing risk/benefit when considering inadequate vitamin D status versus over-exposure to sunlight, and the International Agency for Research on Cancer has argued for more research to address questions about UVR as a means of increasing vitamin D levels ${ }^{17}$. With this in mind we sought to address the question: is there evidence to show whether vitamin $\mathrm{D}$ levels can be maintained despite extended periods of little or no exposure to sunlight?

\section{Materials and methods}

\section{Selection of studies for review}

Scoping searches were performed between August 2008 and April 2009 with input from an information specialist to assist in development of the search strategy. Subsequently, following the development of a study protocol (supplementary material), relevant published articles were identified through searches of through Medline (1948 to July 2012), Embase (1980 to July 2012), Cochrane Central Database, Cochrane Systematic Reviews, Cochrane Clinical Trials Registry, Database of Abstracts and Reviews (1986 to July 2012), Health Technology Assessment Database, NHS Economic Evaluation Database (1994 to July 2012), Centre for Research and Dissemination Research in Progress Database, Current Controlled Trials, National Research Registry archive and Cancer Research UK research register. Bibliographies of papers meeting inclusion criteria were used to search for additional relevant publications and recent issues of major journals were hand searched. Given the size of the body of evidence, including effects of age and illness on 
circulating vitamin D concentrations, this review focused on healthy adults, with the protocol being altered to reflect this. Only English language articles were included. All searches were continually updated during the course of the review and all references stored in an Endnote database.

For online searches, synonyms of diet, dietary supplementation and ultraviolet radiation were used to create search strings (see supplementary material). A study design facet within the search term was not included, as nomenclature for observation studies is not standardised. Observational studies reporting on the relationship between UVR and serum vitamin D levels in healthy adult populations were included with no exclusions based upon ethnicity, gender or skin type.

Two independent investigators (SAR and MC/LMV/AF) screened titles and abstracts where available from the searches and another author $(\mathrm{EH})$ acted as arbiter where necessary. When there was insufficient information to make an accurate decision about quality or eligibility of an article for inclusion, or numerical data could not be extracted, further information was sought from the author. Papers were excluded where participants were in long-term care, had an intercurrent illness, serum vitamin D was not measured, on drugs that affect vitamin D metabolism, and in the case of duplicate data. We have not listed all excluded studies as they were in excess of 42,000 papers.

\section{Data extraction and study quality assessment}

Data extraction was undertaken by two reviewers (SAR and MR/LMV/AF) and entered into an electronic record. Uncertainty was resolved in the same manner as for selection of abstracts. Methodological quality of each study was 
assessed through composition of a validity score (see supplementary material) with studies rejected below an agreed score.

\section{Data analysis}

Data on serum $250 H D$ levels from each article were displayed graphically as mean and standard deviation. Where study participants were divided into different groups based on ethnicity or gender, these groups were maintained during data extraction/synthesis processes and labelled as different datasets in graphs. Studies with a mean $25 \mathrm{OHD}$ value $>50 \mathrm{nmol} / \mathrm{l}$ (equivalent to $>20 \mathrm{ng} / \mathrm{ml}$ ) were designated as demonstrating that many individuals within the investigated population had adequate $25 \mathrm{OHD}$ levels at time of assessment.

\section{Results}

A systematic review was conducted according to the structure and methods outlined by the Centre for Reviews and Dissemination (2008) and PRISMA statement ${ }^{18}$. To assess whether UVR exposure is necessary to maintain adequate vitamin D levels, we identified and evaluated studies reporting on serum $25 \mathrm{OHD}$ in groups of people living in circumstances of absent or negligible UVR to determine whether all healthy adults in these situations have inadequate serum 25OHD.

The search identified 42,695 references, of which 8,489 were duplicates (figure 1). Following screening of title and abstract by two independent reviewers, another 33,905 were excluded, leaving 301 references requiring full text review, with 3 additional papers found on review of reference lists therein. Forty-one studies were included in the final analysis including 11 
cross-sectional, 25 observational cohort, 1 interventional cohort, 1 casecontrol and 3 randomised controlled trials. Each study was represented by one of four categories; (1) seasonal variation in serum 250HD (studies including wintertime serum 25OHD levels), (2) location-related minimal UVR exposure (studies on participants in polar regions), (3) clothing-related minimal UVR exposure and (4) employment-related minimal UVR exposure.

\section{Seasonal variation in serum vitamin D}

Skin synthesis of vitamin D depends on incident UVB radiation and the annual fluence of UVB radiation at $310 \mathrm{~nm}$ at $60^{\circ}, 45^{\circ}$ and $30^{\circ}$ latitude are $20 \%, 40 \%$ and $65 \%$ respectively of the annual fluence at the Equator. The lower solar elevation angle at higher latitudes and higher levels of ozone are thought to account for this variation. Out of 27 datasets (comprising 3,018 individuals between latitudes $22^{\circ} \mathrm{S}$ and $53^{\circ} \mathrm{N}$ ) from 20 studies $^{19-38}, 20$ demonstrated mean serum 25OHD levels higher in summer than winter (figure 2). In six datasets, only a wintertime level was measured. There is evidence that ambient UVR in winter is insufficient to generate vitamin $D$ at higher latitudes in nonpolar regions, e.g. no previtamin D3 is produced from November to February inclusive in Boston, USA $\left(42^{\circ} \mathrm{N}\right)$, and between October and March in Edmonton, Canada $\left(52^{\circ} \mathrm{N}\right)^{39}$. In 10 datasets, comprising 625 subjects, mean serum $25 \mathrm{OHD}$ was adequate $(>50 \mathrm{nmol} / \mathrm{L}$ ) during wintertime when UVR during those months would not have acted as a source of serum vitamin $\mathrm{D}$ for 19 of the 27 datasets. Although one study reported that black females in Toronto, Canada had mean serum 25OHD levels $>50 \mathrm{nmol} / \mathrm{L}$ in winter and summer ${ }^{23}$, four data sets of participants failed to reach an 
adequate mean serum $25 \mathrm{OHD}$ level in summertime; these comprised nonHispanic black women and Hispanic women in Galveston, Texas ${ }^{29}$, black women in Boston ${ }^{20}$ and a heterogenous group in Paris ${ }^{25}$.

\section{Location-related minimal UVR exposure}

These nine polar region studies included 556 individuals $^{40-48}$. Mean serum $250 H D$ remained adequate in four of twelve datasets during the prolonged winter season during which winter UVR does not contribute to serum vitamin D levels (figure 3). Some participants are likely to have maintained serum $250 H D$ by dietary supplementation; those in Skejvoy consumed a traditional diet comprising regular fish-liver which contains high quantities of vitamin $D^{41}$ and the Tromso study ascribed the adequate $250 \mathrm{HD}$ levels to diet, including foods (e.g. margarine) fortified with vitamin $D^{40}$. Two groups of migrant workers from the UK and Australia did not consume vitamin D supplements or a fortified diet, yet all participants in these studies maintained an adequate serum 250 HD level throughout the year $^{43,45}$.

\section{Clothing-related minimal UVR exposure}

Nine datasets in six studies comprised 276 veiled women living between $24^{\circ} \mathrm{N}$ and $41^{\circ} \mathrm{N}$ (figure 4$)^{49-54}$. Eight datasets reported mean $250 \mathrm{HD}$ levels classed as deficient, but one group of 30 veiled women had a mean serum $25 \mathrm{OHD}$ of $83 \pm 40 \mathrm{nmol} / \mathrm{L}^{49}$. Most participants in this latter group led an indoor life in the outskirts of Adana, Turkey with only $33 \%$ receiving direct sunlight to uncovered face and distal extremities in the courtyards of their homes. 


\section{Employment-related minimal UVR exposure}

These six studies contained 361 participants receiving little or no UVR due to their occupational environment (figure 5) ${ }^{55-60}$. Most had deficient 25OHD levels, but the submariners studied by Duplessis et al. had adequate mean serum 25OHD. In that study, some individuals received $400 \mathrm{IU}$ of vitamin D supplementation daily and a vitamin D fortified diet. However, $>50 \%$ of submariners who consumed a fortified diet without additional supplementation also maintained adequate serum $250 \mathrm{HD}$ levels ${ }^{58}$.

\section{Discussion}

This systematic review focussed on studies measuring 25OHD in healthy adults exposed to minimal UVR to see whether it is possible for them to maintain serum vitamin D levels without UVR exposure. Many people have higher serum 25OHD in summer than in winter, and this increase during summer months likely relates to skin synthesis of vitamin $D$ following sun exposure. However, the results of this review indicate that many people can maintain adequate serum 25OHD levels in the absence or paucity of sunlight for several months and possibly on a longer-term basis. As adequate levels of vitamin D could be maintained in $>50 \%$ of participants in 17 of 56 groups amassed from 41 studies, this is a reproducible observation found in population groups in many different parts of the world. Whilst subjects with low dietary vitamin $D$ intake living in areas of high sun-exposure may obtain significant amounts of vitamin D from UVR, the current study suggests that many individuals obtain little or no vitamin $D$ from sunshine for several months of the year. 
The vast number of publications on vitamin $D$ makes it difficult to form a valid evidence-based opinion in a short timeframe on whether UVR is necessary for maintenance of adequate vitamin $D$ levels, highlighting a need for this systematic review. Currently, many position statements advocate sun exposure for the maintenance of adequate vitamin D levels, an approach that requires caution given the known negative implications of excessive UV exposure. As the data in figure 2 demonstrate, it is also not sufficient to presume that individuals in sunny environments will necessarily be vitamin D replete in summertime, a finding well and repeatedly supported by other published studies ${ }^{61-64}$.

Whilst there is a generally agreed level of insufficient serum 25OHD $(25 \mathrm{nmol} / \mathrm{L})$ there is no universally agreed minimum or optimum serum $25 \mathrm{OHD}$ level $^{65-69}$. Having reviewed the literature, we opted for 250HD levels of adequate $(>50 \mathrm{nmol} / \mathrm{L})$ and optimal $(>75 \mathrm{nmol} / \mathrm{L})$ in common with some experts in the field ${ }^{68,70-73}$. This review concentrated on adequate $250 \mathrm{HD}$ levels and our conclusions relate primarily to this outcome. However the inclusion of lines to indicate both adequate and optimal levels of 25OHD in figures $2-5$ does allow identification of the studies where individuals reach optimal 25OHD levels.

It is clear that UVR is an important source of vitamin D in many population groups $^{74-76}$. Whilst some patterns of sunlight exposure have benefits (notably a reduction in lifetime melanoma risk with occupational sun exposure ${ }^{77}$ ), there is strong evidence that individuals who overexpose themselves to sunlight carry a significantly increased risk of cutaneous carcinogenesis and/or cataract. There is uncertainty about the optimal dietary vitamin D intake and 
the acceptable level of exposure to UVB that would permit vitamin D synthesis without increasing UVR-related disease. Although a consensus statement from various societies suggests that suberythemal doses of midday UVR can be helpful in generating vitamin $\mathrm{D}^{13}$, suberythemal UVR doses are known to cause a variety of effects in skin, including DNA damage and p53 upregulation $^{78,79}$

In order to derive dietary reference values for vitamin $\mathrm{D}$, the dietary requirement for vitamin $D$ when skin-derived vitamin $D$ is very low or negligible needs to be defined. In the UK, there is no dietary reference value for vitamin $D$ for normal adults, which implies no absolute need for a dietary intake and that endogenous production will meet vitamin D requirements. This is unlikely to be correct and indeed in the UK, margarines are fortified with vitamin $D$ by law in an attempt to ensure an intake of vitamin $D$ by the whole population ${ }^{80}$. Recommendations exist for supplementing vitamin $D$ in pregnant women, infants and children up to 5 years of age ${ }^{65,81}$. Additionally, in population groups who do not take supplements and are not exposed to sunlight during winter months, vitamin $\mathrm{D}$ status can become very low during winter and early spring, and it is apparent from the data in figures $2-5$ that many people are deficient in vitamin $\mathrm{D}$ in winter and/or spring despite vitamin D stores from summer exposure ${ }^{82,83}$. However, a two-compartment model of vitamin $\mathrm{D}$, with summer sun resulting in prolonged tissue storage and subsequent slow release of vitamin D has been postulated by Diffey in $2012^{84}$ and was proposed as the mechanism for the maintenance of vitamin $D$ during the winter months in the British population. Such a model, where vitamin D is stored in fat, could have implications for those groups studied over the winter 
months and for those groups working in locations with little or no UVR presented in this review. Unfortunately, the documentation of individual subject's lifestyle and diet prior to each study is limited and makes the role of these factors difficult to determine from the studies included in this review. As reported in the literature, Figures 2 - 5 illustrate that increasing dietary vitamin D intake through fortification and/or supplementation can increase $25 \mathrm{OHD}$ to adequate levels. Studies treating deficient multi-ethnic populations or non-Western immigrants with sunlight exposure, dietary modification or vitamin D supplementation, have documented that fatty fish and vitamin $D$ supplementation are the greatest modifiable contributors to vitamin D sufficiency ${ }^{85,86}$. Recent interventional studies suggest that the recommended daily vitamin $D$ intake for certain groups set by scientific advisory committees in the UK and USA ${ }^{65,73}$ are reasonable ${ }^{87}$. Cashman et al. using mathematical modelling found that it would be possible for $97.5 \%$ of "sunshine avoiders" in the UK and Ireland to sustain serum $25 \mathrm{OHD}>50 \mathrm{nmol} / \mathrm{L}$ with a dietary intake of $31.0 \mathrm{~g} /$ day (equivalent to $1,240 \mathrm{IU} /$ day) vitamin $D^{88}$. Whereas some recent studies in post-menopausal women have recorded vitamin D levels, dietary intake and sun-exposure in greater detail than in previous groups ${ }^{89,90}$, no trial has been conducted in healthy subjects receiving little or no UVR consuming this suggested daily vitamin D intake. Whilst we must consider a role for preceding UVR in the maintenance of adequate vitamin D levels in some of the studies covered in this review, in the study on veiled women from Adana, Turkey $^{49}$ all the women had worn traditional dress covering the whole body except the eyes for at least the previous 3 years (with a mean duration of 8.87 years), yet the mean serum $25 \mathrm{OHD}$ was $83 \pm 40 \mathrm{nmol} / \mathrm{L}$. None of the women 
in that study were on vitamin D supplementation and $66.7 \%$ claimed never to be exposed to direct sunlight. In addition, the authors reported that regular food products are not fortified with vitamin D in Turkey, however, individual dietary intake was not documented, the sample size was small and $33 \%$ of subjects did "sometimes" expose their face, lower parts of the legs and arms to direct sunlight (20\% rarely, 3.3\%<1 hour a week, 10\% >2 hours a week), all of which may have contributed to their vitamin $D$ results.

A number of studies have looked at associations between vitamin $D$ and skin cancer risk and/or outcome. It has been reported that vitamin $D$ inhibits growth of melanoma cell lines in vitro ${ }^{91}$ and an inverse correlation has been documented between higher 25OHD levels at time of melanoma diagnosis and Breslow thickness, as well as with risk of relapse and death ${ }^{92}$. Another study which introduced calcium and vitamin D supplementation at the time of non-melanoma skin cancer diagnosis found a reduction in subsequent melanoma incidence ${ }^{93}$. In addition, vitamin $\mathrm{D}$ receptor deficient mice have been reported to exhibit a higher incidence of non-melanoma skin cancer ${ }^{94}$. However, many human studies report inconsistent associations between skin cancer and serum 25OHD levels ${ }^{95-101}$, something which may be confounded as a result of elevated serum $25 \mathrm{OHD}$ levels arising from high dietary intake/supplementation or alternatively from excessive UVR exposure. In order to promote adequate levels of vitamin D while avoiding the negative sequelae of UVR, public health campaigns encouraging a high vitamin D diet or supplements to healthy adults could positively impact on the health of the individual. Nonetheless, some concerns also exist about long-term fortification and/or supplementation with dietary vitamin $D^{83}$, thus advocating intake of 
foods naturally rich in vitamin D may be more appropriate where diets are low in vitamin $\mathrm{D}^{41}$.

There were several challenges in this review. The numbers of studies documenting serum $25 \mathrm{OHD}$ in relation to natural sun-exposure are limited and as the data within studies is generally pooled from groups of participants rather than individuals, it does not inform on sun exposure and dietary details of each individual. The use of wintertime $250 \mathrm{HD}$ levels is likely to circumvent the risk that subjects are receiving additional, unrecognised sun exposure, but reliance on subjects' retrospective recall is a weakness of this approach. Similarly, the data in studies on clothing or employment-related minimal UVR exposure were reliant on the veracity of participants documenting their limited sun exposure. Various factors influence vitamin D status or responses to UVR, including diet, ethnicity and skin type, and articles often did not comment in detail on these. Exclusion of studies in which subjects were not identified as healthy, were in long-term care, institutionalised or on drugs which could affect vitamin D levels or metabolism means these results cannot be extrapolated to those groups of people. Since the review focussed on healthy adults, further work is needed to clarify whether the results are relevant to other age groups. As there were very few randomised controlled trials and controlled trials on UVR and vitamin D, we also considered evidence from cohort and case-control studies and case series despite their higher potential for bias and this heterogeneity meant that it was not possible to pool the results and conduct a meta-analysis. Additional shortcomings were the size of studies, some being underpowered to detect clinically relevant differences. Despite these shortcomings, the repeated observation 
that many people have adequate $250 \mathrm{HD}$ levels during periods of negligible UVR suggests it is possible for a significant proportion of individuals to maintain adequate vitamin D levels, at least for several months, without the necessity of on-going UVR exposure.

This systematic review also had a number of strengths. It was conducted according to rigorous methods ${ }^{18,102}$. The use of synonyms of search terms and searching widely in databases, registries, published literature plus consultation with experts in the field, minimised risk of publication bias. While the findings of this review provide useful information for evidence-based public health recommendations at the present time, more research is required in the form of prospective clinical trials which accurately record vitamin $D$ intake, its UVR-related synthesis and its storage in the participants throughout the year, in particular in situations of negligible UVR exposure.

\section{Acknowledgements}

We are grateful to Liz Payne (independent information specialist) for assistance in search strategy development and Ann Prentice, Inez Schoenmakers and Roger Francis for advice and review of manuscript. AAJ receives support for the Southampton Biomedical Research Centre for Nutrition from NIHR. 


\section{Figure legends}

Fig 1. Flow diagram for study selection.

Fig 2. Serum 25OHD (mean +/- SD where documented) in studies which reported on wintertime and/or seasonal variation in vitamin $D$ levels in humans in relation to latitude ${ }^{19-38}$. In studies where two mean (+/- SD) values are provided (and tied together by a broken line), the winter serum 25OHD is on the left and the summer serum $25 \mathrm{OHD}$ is on the right. Studies highlighted by an asterix $\left({ }^{*}\right)$ are those which were conducted at latitudes that experience insufficient UVR for synthesis of vitamin D during winter and in which the mean wintertime $25 \mathrm{OHD}$ value is $>50 \mathrm{nmol} / \mathrm{L}$.

Fig 3. Serum $250 H D$ (mean +/- SD) in studies which have recorded vitamin $D$ levels in participants residing in polar regions for prolonged periods during the winter season ${ }^{40-48}$. In studies with two mean (+/- SD) serum 25OHD values (connected by a broken line), the winter and the summer values are on the left and right respectively. Studies denoted with an asterix $\left({ }^{*}\right)$ are those with a mean wintertime $25 \mathrm{OHD}$ value $>50 \mathrm{nmol} / \mathrm{L}$.

Fig 4. Serum 25OHD (mean +/- SD) in studies which measured vitamin D levels in subjects exposed to minimal UVR as a result of clothing attire ${ }^{49-54}$. A mean serum $25 \mathrm{OHD}$ value above adequate levels $(>50 \mathrm{nmol} / \mathrm{L})$ is seen in the study marked with an asterix $\left({ }^{*}\right)$. 
Fig 5. Serum 25OHD (mean +/- SD) in studies which documented vitamin D levels in subjects receiving minimal UVR exposure as a result of certain types of employment ${ }^{55-60}$. An asterix $\left(^{*}\right)$ highlights the groups of participants in which the mean $25 \mathrm{OHD}$ value is $>50 \mathrm{nmol} / \mathrm{L}$.

\section{Supplementary material}

Protocol

Search Details

\section{References}

1 Bischoff-Ferrari HA, Willett WC, Wong JB et al. Prevention of nonvertebral fractures with oral vitamin $\mathrm{D}$ and dose dependency: $\mathrm{a}$ meta-analysis of randomized controlled trials. Arch Intern Med 2009; 169: 551-61.

2 Dobnig H, Pilz S, Scharnagl $\mathrm{H}$ et al. Independent association of low serum 25-hydroxyvitamin D and 1,25-dihydroxyvitamin D levels with all-cause and cardiovascular mortality. . Arch Intern Med 2008; 168: 1340-9.

3 Munger KI, Levin LI, Hollis BW et al. Serum 25-hydroxyvitamin d levels and risk of multiple sclerosis. Jama 2006; 296: 2832-8.

4 Merlino LA, Curtis J, Mikuls TR et al. Vitamin D Intake Is Inversely Associated With Rheumatoid Arthritis: Results From the lowa Women's Health Study. Arthritis \& Rheum 2004; 50: $72-7$.

5 Giovannucci E, Liu Y, Rimm EB et al. Prospective study of predictors of vitamin $D$ status and cancer incidence and mortality in men. $J$ Natl Cancer Inst 2006; 98: 451-9.

6 Melamed ML, Michos ED, Post W et al. 25-hydroxyvitamin D levels and the risk of mortality in the general population. Arch Intern Med 2008; 168: 1629-37.

7 Ashwell M, Stone EM, Stolte $\mathrm{H}$ et al. UK Food Standards Agency Workshop Report: an investigation of the relative contributions of diet and sunlight to vitamin D status. Br J Nutr 2010; 104: 603-11.

8 Prentice A. Vitamin D deficiency: A global perspective. Nutr Rev 2008; 66: S153-S64.

9 Hypponen E, Power C. Hypovitaminosis D in British adults at age $45 \mathrm{y}$ : nationwide cohort study of dietary and lifestyle predictors. Am J Clin Nutr 2007; 85: 860-8.

10 Holick MF, Holick MF. Evolution and function of vitamin D. Recent Results Cancer Res 2003; 164: 3-28. 
11 Moan J, Porojnicu AC, Dahlback A et al. Addressing the health benefits and risks, involving vitamin $\mathrm{D}$ or skin cancer, of increased sun exposure. Proc Natl Acad Sci U S A 2008; 105: 668-73.

12 Cancer Council Australia. Risks and benefits of sun exposure position statement. In. 2007; http://www.cancer.org.au/cancer-controlpolicy/position-statements/sun-smart/.

13 Cancer Research UK. Joint position statement issued to provide vitamin D clarity. In. 2010; http://www.cancerresearchuk.org/cancerinfo/news/archive/cancernews/2010-12-16-Joint-position-statementissued-to-provide-vitamin-D-clarity-.

14 Lucas R, McMichael T, Smith W et al. Solar ultraviolet radiation: global burden of disease from solar ultraviolet radiation. . In: Environmental Burden of Disease Series No. 13 (Prüss-Üstün A, Zeeb H, Mathers C et al., eds). Geneva: World Health Organisation. 2009; 1-250.

15 Diffey $\mathrm{BL}$. Modelling the seasonal variation of vitamin $\mathrm{D}$ due to sun exposure. Br J Dermatol 2010; 162: 1342-8.

16 Rhodes LE, Webb AR, Fraser $\mathrm{HI}$ et al. Recommended Summer Sunlight Exposure Levels Can Produce Sufficient (>=20ng/ml) but Not the Proposed Optimal (>=32ng/ml) 25(OH)D Levels at UK Latitudes. J Invest Dermatol 2010; 130: 1411-8.

17 International Agency for Research on Cancer. Vitamin D and cancer. In: IARC Working group reports vol. 5. Lyon: IARC. 2008; http://www.iarc.fr/en/publications/pdfs-online/wrk/wrk5/Report_VitD.pdf.

18 Moher D, Liberati A, Tetzlaff JE et al. Preferred reporting items for systematic reviews and meta-analyses: the PRISMA statement. Ann Intern Med 2009; 151.

19 Hall LM, Kimlin MG, Aronov PA et al. Vitamin D intake needed to maintain target serum 25-hydroxyvitamin D concentrations in participants with low sun exposure and dark skin pigmentation is substantially higher than current recommendations. J Nutr 2010; 140: 542-50.

20 Harris SS, Dawson-Hughes B. Seasonal changes in plasma 25hydroxyvitamin $\mathrm{D}$ concentrations of young American black and white women. . Am J Clin Nutr 1998; 67: 1232-6.

21 Tangpricha V, Pearce EN, Chen TC et al. Vitamin D insufficiency among free-living healthy young adults. Am J Med 2002; 112: 659-62.

22 Gozdzik A, Barta JL, Wu H et al. Low wintertime vitamin D levels in a sample of healthy young adults of diverse ancestry living in the Toronto area: associations with vitamin $\mathrm{D}$ intake and skin pigmentation. $B M C$ Public Health 2008; 8: 336.

23 Veith R, Cole DE, Hawker GA et al. Wintertime vitamin D insufficiency is common in young Canadian women, and their vitamin $D$ intake does not prevent it. . Eur J Clin Nutr 2001; 55: 1091-7.

24 Nelson ML, Blum JM, Hollis BW et al. Supplements of 20 microg/d cholecalciferol optimized serum 25-hydroxyvitamin D concentrations in $80 \%$ of premenopausal women in winter. J Nutr 2009; 139 (3): 540-6.

25 Guillemant J, Guillemant S. Acute PTH response to oral calcium load and seasonal variation of vitamin $D$ status in healthy young adult subjects. Eur J Clin Nutr 1996; 50: 469-72. 
26 Beadle PC, Burton JL, Leach JF. Correlation of seasonal variation of 25-hydroxycalciferol with UV radiation dose. Brit J Dermatol 1980; 102: 289.

27 McLaughlin M, Raggatt PR, Fairney A et al. Seasonal variations in serum 25-hydroxycholecalciferol in healthy people. Lancet 1974; 1: 536-8.

28 Juttmann JR, Visser TJ, Buurman C et al. Seasonal fluctuations in serum concentrations of vitamin D metabolites in normal subjects. $\mathrm{Br}$ Med J (Clin Res Ed) 1981; 282: 1349-52.

29 McKinney K, Breitkopf CR, Berenson AB. Association of race, body fat and season with vitamin $D$ status among young women: A crosssectional study. Clin Endocrinol (Oxf) 2008; 69: 535-41.

30 McKenna MJ, Freaney R, Byrne P et al. Safety and efficacy of increasing wintertime vitamin $\mathrm{D}$ and calcium intake by milk fortification. In: QJM : monthly journal of the Association of Physicians. 1995; 8958.

31 O'Sullivan M, Nic Suibhne T, Cox G et al. High prevalence of vitamin D insufficiency in healthy Irish adults. Ir J Med Sci 2008; 177: 131-4.

32 Webb AR, Kift R, Durkin MT et al. The role of sunlight exposure in determining the vitamin $\mathrm{D}$ status of the U.K. white adult population. $\mathrm{Br} \mathrm{J}$ Dermatol 2010; 163 (5): 1050-5.

33 Thieden E, Philipsen PA, Heydenreich $\mathrm{J}$ et al. Vitamin D level in summer and winter related to measured UVR exposure and behavior. Photochem Photobiol 2009; 85: 1480-4.

34 Mazess RB, Barden HS, Christiansen C. Bone mineral and vitamin D in Aleutian Islanders. Am J Clin Nutr 1985; 42: 143-6.

35 Maeda SS, Kunii IS, Hayashi L et al. The effect of sun exposure on 25hydroxyvitamin $\mathrm{D}$ concentrations in young healthy subjects living in the city of Sao Paulo, Brazil. Braz J Med Biol Res 2007; 40: 1653-9.

36 Livesey J, Elder P, Ellis MJ et al. Seasonal variation in vitamin D levels in the Canterbury, New Zealand population in relation to available UV radiation.[see comment]. NZ Med J 2007; 120: U2733.

37 Levis S, Gomez A, Jimenez $\mathrm{C}$ et al. Vitamin d deficiency and seasonal variation in an adult South Florida population. J Clin Endocrinol Metab 2005; 90: 1557-62.

38 Kobayashi T. Nutritional aspects of vitamin $D$ and its metabolites in Japanese children and adults. J Bone Miner Metab 1999; 17: 151-63.

39 Webb AR, Kline L, Holick MF. Influence of season and latitude on the cutaneous synthesis of vitamin D3: exposure to winter sunlight in Boston and Edmonton will not promote vitamin D3 synthesis in human skin. J Clin Endocrinol Metab 1988; 67: 373-8.

40 Vik T, Try K, Stromme JH. The vitamin D status of man at 70 degrees north. Scand J Clin Lab Invest 1980; 40: 227-32.

41 Brustad M, Sandanger T, Aksnes L et al. Vitamin D status in a rural population of northern Norway with high fish liver consumption. Public Health Nutr 2004; 7: 783-9.

42 Brustad M, Edvardsen K, Wilsgaard T et al. Seasonality of UV-radiation and vitamin D status at 69 degrees north. Photochem Photobiol Sci 2007; 6: 903-8. 
43 Pitson GA, Lugg DJ, Roy CR. Effect of seasonal ultraviolet radiation fluctuations on vitamin $\mathrm{D}$ homeostasis during an Antarctic expedition. Eur J Appl Physiol 1996; 72: 231-4.

44 Yonei $\mathrm{T}$, Hagino $\mathrm{H}$, Katagiri $\mathrm{H}$ et al. Bone metabolic changes in Antarctic wintering team members. Bone 1999; 24: 145-50.

45 Fairney A, Fry J, Lipscomb A. The effect of darkness on vitamin D in adults. Postgrad Med J 1979; 55: 248-50.

46 Smith SM, Gardner KK, Locke J et al. Vitamin D supplementation during Antarctic winter. Am J Clin Nutr 2009; 89: 1092-8.

47 Oliveri MB, Mautalen C, Bustamante L et al. Serum levels of 25hydroxyvitamin $\mathrm{D}$ in a year of residence on the Antarctic continent. Eur J Clin Nutr 1994; 48: 397-401.

48 Brustad M, Alsaker E, Engelsen $\mathrm{O}$ et al. Vitamin D status of middleaged women at 65-71 degrees $\mathrm{N}$ in relation to dietary intake and exposure to ultraviolet radiation. Public Health Nutr 2004; 7: 327-35.

49 Guzel R, Kozanoglu E, Guler-Uysal F et al. Vitamin D status and bone mineral density of veiled and unveiled Turkish women. J Womens Health Gend Based Med 2001; 10: 765-70.

50 Alagol $\mathrm{F}$, Shihadeh $\mathrm{Y}$, Boztepe $\mathrm{H}$ et al. Sunlight exposure and vitamin D deficiency in Turkish women. J Endocrinol Invest 2000; 23: 173-7.

51 Budak N, Cicek B, Sahin $\mathrm{H}$ et al. Bone mineral density and serum 25hydroxyvitamin $\mathrm{D}$ level: Is there any difference according to the dressing style of the female university students. Int J Food Sci Nutr 2004; 55: 569-75.

52 Gharaibeh MA, Stoecker BJ. Assessment of serum 25(OH)D concentration in women of childbearing age and their preschool children in Northern Jordan during summer. Eur J Clin Nutr 2009; 63 (11): 1320-6.

53 El-Sonbaty MR, Naser A-G. Vitamin D deficiency in veiled Kuwaiti women. Eur J Clin Nutr 1996; 50: 315-8.

54 Dawodu A, Absood G, Patel $\mathrm{M}$ et al. Biosocial factors affecting vitamin $D$ status of women of childbearing age in the United Arab Emirates. $J$ Biosoc Sci 1998; 30: 431-7.

55 Islam MZ, Shamim AA, Kemi V et al. Vitamin D deficiency and low bone status in adult female garment factory workers in Bangladesh.[see comment]. Br J Nutr 2008; 99: 1322-9.

56 Sarikaya S, Ozdolap S, Mungan AG et al. Effect of underground working on vitamin $D$ levels and bone mineral densities in coal miners: A controlled study. J Int Med Res 2006; 34: 362-6.

57 Dlugos DJ, Perrotta PL, Horn WG. Effects of the submarine environment on renal-stone risk factors and vitamin D metabolism. Undersea Hyperb Med 1995; 22: 145-52.

58 Duplessis CA, Harris EB, Watenpaugh DE et al. Vitamin D supplementation in underway submariners. Aviat Space Environ Med 2005; 76: 569-75.

59 Luria T, Matsliah Y, Adir Y et al. Effects of a prolonged submersion on bone strength and metabolism in young healthy submariners. Calcif Tissue Int; 86: 8-13. 
60 Smith SM, Zwart SR, Block G et al. The nutritional status of astronauts is altered after long-term space flight aboard the International Space Station. J Nutr 2005; 135: 437-43.

61 Goswami R, Gupta N, Ray D et al. Pattern of 25-hydroxy vitamin D response at short (2 month) and long (1 year) interval after 8 weeks of oral supplementation with cholecalciferol in Asian Indians with chronic hypovitaminosis D. Br J Nutr 2008; 100: 526-9.

62 Kimlin M, Harrison S, Nowak M et al. Does a high UV environment ensure adequate vitamin D status? J Photochem Photobiol B 2007; 89: 139-47.

63 Unger MD, Cuppari L, Titan SM et al. Vitamin D status in a sunny country: Where has the sun gone? Clin Nutr; 29 (6): 784-8.

64 Soontrapa S, Bunyaratavej N, Rojanasthien S et al. Vitamin D status of Thai premenopausal women. J Med Assoc Thai 2009; 92 Suppl5: S1720.

65 Scientific Advisory Committee on Nutrition. Update on Vitamin D: Position statement by the Scientific Advisory Committee on Nutrition. In: (Department of Health and the Food Standards Agency, ed). London: TSO. 2007.

66 Hanley DA, Davison KS, Hanley DA et al. Vitamin D insufficiency in North America. J Nutr 2005; 135: 332-7.

67 Hollis BW, Hollis BW. Circulating 25-hydroxyvitamin D levels indicative of vitamin D sufficiency: implications for establishing a new effective dietary intake recommendation for vitamin D. J Nutr 2005; 135: 317-22.

68 Bischoff-Ferrari HA, Giovannucci E, Willett WC et al. Estimation of optimal serum concentrations of 25-hydroxyvitamin $D$ for multiple health outcomes. Am J Clin Nutr 2006; 84: 18-28.

69 Priemel M, von Domarus C, Klatte TO et al. Bone mineralisation defects and vitamin D deficiency: histomorphometric analysis of iliac crest bone biopsies and circulating 25-hydroxyvitamin D in 675 patients. J Bone Miner Res 2010; 25: 305-12.

70 Friedman CF, DeMichele A, Su HI et al. Vitamin D deficiency in post menopausal breast cancer survivors. J Womens Health 2012; 21: 45662.

71 Binkley N, Ramamurthy R, Krueger D. Low vitamin D status: definition, prevalence, consequences and correction. Rheum Dis Clin North Am 2012; 38: 45-59.

72 Veith R, Bischoff-Ferrari $\mathrm{H}$, Boucher BJ et al. The urgent need to recommend an intake of vitamin $\mathrm{D}$ that is effective. Am $\mathrm{J}$ Clin Nutr 2007; 85: 649-50.

73 Institute of Medicine (US) Committee to Review Dietary Reference Intakes for Vitamin D and Calcium. Dietary Reference Intakes for Calcium and Vitamin D. In: (Ross AC, Taylor CL, Yaktine AL, eds). Washingotn (DC): National Academies Press (US). 2011.

74 Brot $\mathrm{C}$, Vestergaard $\mathrm{P}$, Kolthoff $\mathrm{N}$ et al. Vitamin $\mathrm{D}$ status and its adequacy in healthy Danish perimenopausal women: relationships to dietary intake, sun exposure and serum parathyroid hormone. Br J Nutr 2001; 86 Suppl 1: S97-103.

75 Sedrani SH, Elidrissy AW, El Arabi KM. Sunlight and vitamin D status in normal Saudi Subjects. Am J Clin Nutr 1983; 38: 129-32. 
76 Webb AR, Pilbeam $\mathrm{C}$, Hanafin $\mathrm{N}$ et al. An evaluation of the relative contributions of exposure to sunlight and of diet to the circulating concentrations of 25-hydroxyvitamin $D$ in an elderly nursing home population in Boston. Am J Clin Nutr 1990; 51: 1075-81.

77 Kennedy C, Bajdik CD, Willemze et al. The influence of painful sunburns and lifetime sun exposure on the risk of actinic keratoses, seborrheic warts, melanocytic naevi, atypical naevi, and skin cancer. $J$ Invest Dermatol 2003; 120: 1087-93.

78 Healy E, Reynolds NJ, Smith MD et al. Dissociation of Erythema and p53 Protein Expression in Human Skin Following UVB Irradiation, and Induction of p53 Protein and mRNA Following Application of Skin Irritants. J Investig Dermatol 1994; 103: 493-9.

79 Seité S, Fourtanier A, Moyal D et al. Photodamage to human skin by suberythemal exposure to solar ultraviolet radiation can be attenuated by sunscreens: a review. Br J Dermatol 2010; 163: 903-14.

80 Department of Health and Social Security. Rickets and osteomalacia: report on health and social subjects number 19. In, Vol. 19. London: HMSO. 1980.

81 National Institute for Clinical Excellence. Improving the nutrition of pregnant and breastfeeding mothers and children in low-income households In: NICE Public Health Guidance, Vol. 11. London. 2008.

82 Lawson DEM, Douglas J, Lean $\mathrm{M}$ et al. Estimation of vitamin D3 and 25-hydroxyvitamin D3 in muscle and adipose tissue of rats and man. Clin Chim Acta 1986; 157: 175-81.

83 Macdonald HM, Mavroeidi A, Reid DM et al. Sunlight or diet: what is the answer for providing sufficient vitamin $\mathrm{D}$ in the U.K.? Br J Dermatol 2010; 163: 434-5.

84 Diffey BL. Modelling vitamin D status due to oral intake and sun exposure in an adult British population. Br J Nutr 2013; 110: 569-577

85 Van Der Meer IM, Boeke AJP, Lips P et al. Fatty fish and supplements are the greatest modifiable contributors to the serum 25-hydroxyvitamin D concentration in a multiethnic population. Clin Endocrinol (Oxf) 2008; 68: 466-72.

86 Wicherts IS, Boeke AJP, Meer IM et al. Sunlight exposure or vitamin D supplementation for vitamin D-deficient non-western immigrants: a randomized clinical trial. Osteoporos Int 2010; 22: 873-82.

87 Cashman KD, FitzGerald AP, Viljakainen HT et al. Estimation of the dietary requirement for vitamin $\mathrm{D}$ in healthy adolescent white girls. $A m$ J Clin Nutr 2011; 93: 549-55.

88 Cashman KD, Hill TR, Lucey AJ et al. Estimation of the dietary requirement for vitamin $\mathrm{D}$ in healthy adults. In: Am J Clin Nutr. 2008; 1535-42.

89 Mavroeidi A, O'Neill F, Lee PA et al. Seasonal 25-hydroxyvitamin D changes in British postmenopausal women at 57 degrees $N$ and 51 degrees N: A longitudinal study. J Steroid Biochem Mol Biol 2010; 121: 459-61.

90 Macdonald HM, Mavroeidi A, Fraser WD et al. Sunlight and dietary contributions to the seasonal vitamin D status of cohorts of healthy postmenopausal women living at northerly latitudes: a major cause for concern? Osteoporos Int 2011; 22: 2461-72. 
91 Szyszka P, Zmijewski MA, Slominski AT. New vitamin D analogs as potential therapeutics in melanoma. Expert Rev Anticancer Ther 2012; 12: $585-99$.

92 Newton-Bishop JA, Beswick S, Randerson-Moor J et al. Serum 25hydroxyvitamin D3 levels are associated with breslow thickness at presentation and survival from melanoma. J Clin Oncol 2009; 27: 543944.

93 Tang JY, Fu T, Leblanc E et al. Calcium plus vitamin D supplementation and the risk of nonmelanoma and melanoma skin cacner: post hoc analyses of the women's health initiative randomised controlled trial. J Clin Oncol 2011; 29: 3078-84.

94 Field S, Newton-Bishop JA. Melanoma and vitamin D. Mol Oncol 2011; 5: $197-214$.

95 van der Pols JC, Russell A, Bauer U et al. Vitamin D status and skin cancer risk independent of time outdoors: 11-year prospective study in an Australian community. J Investig Dermatol 2013; 133: 637-41.

96 Liang G, Nan H, Qureshi AA et al. Pre-diagnostic plasma 25hydroxyvitamin $D$ levels and risk of nonmelanoma skin cancer in women. PLOS ONE 2012; 7: e35211.

97 Tang JY, Parimi N, Wu A et al. Inverse association between serum $25 \mathrm{OH}$ vitamin $\mathrm{D}$ levels and non-melanoma skin cancer in elderly men. Cancer Causes Control 2010; 21: 387-91.

98 Freedman DM, Looker AC, Chang SC et al. Prospective study of serum vitamin $D$ and cancer mortality in the United States. J Natl Cancer Inst 2007; 99: 1594-602.

99 Lamberg $A L$, Olesen $A B$, Jensen $A O$. Hip fracture history and risk of nonmelanoma skin cancer: a Danish population study. Clin Epidemiology 2011; 3: 285-93.

100 Eide MJ, Johnson DA, Jacobsen GR et al. Vitamin D and nonmelanoma skin cacner in a health maintenance cohort. Arch Dermatol 2011; 147: 1379-84.

101 Asgari MM, Tang J, Warton ME et al. Association of prediagnostic serum vitamin $D$ levels with the development of basal cell carcinoma. $J$ Invest Dermatol 2010; 130: 1438-43.

102 Centre for Reviews and Dissemination. Systematic Reviews. CRD's guidance for undertaking reviews in health care. In. York: University of York. 2008. 